\title{
Experiência interdisciplinar na Educação Básica e na formação de professores: Artes, Biologia e Geociências
}

\author{
InTERDISCIPLINARY EXPERIENCE IN BASIC EDUCATION AND TRAINING OF TEACHERS: ARTS, BIOLOGY AND GEOSCIENCES
}

\author{
Sarah Gonçalves Duarte ${ }^{1,2}$, Claudia Maria Magalhães Ribeiro Martins² ${ }^{2}$ Luana Graziella Bandeira ${ }^{3}$, Lucio Caetano Carramillo², Marcos Pereira Gervásio4, \\ Maria Dolores Wanderley ${ }^{5}$ \\ 1- Secretaria de Estado de Educação. Rio de Janeiro -, RJ. Emall: sarahpalino@yahoo.com.br \\ 2- Departamento de Geociências, Universidade Federal Rural do Rio de Janeiro. Seropédica, RJ. \\ 3- Faculdade de Clências Médicas, Universidade do Estado do Rio de Janeiro. Rio de Janeiro, RJ. \\ 4- Departamento de Solos, Universidade Federal Rural do Rio de Janeiro. Seropédica, RJ. \\ 5- Departamento de Geologia, Universidade Federal do Rio de Janeiro. Rio de Janeiro, RJ.
}

Abstract: Interdisciplinarity improves the teaching-learning process. Thus, a method merging "Art, Biology and Geosciences" was developed. The aim of this method was to make the high school students of a state college represent through art the origin of the universe, of the planet Earth and of life, following the scale of geological time and the evolution of organisms. After four theoretical classes, the materials produced, collected or donated by universities were presented at the exhibition "A journey in the history of life with Art and Biology". This method was also applied to undergraduate teaching degree students in Biological Sciences and Geography, from two public universities in Rio de Janeiro state (UFRRJ and UFRJ), as an example of a didactic-pedagogical experience of an interdisciplinary method. As a result, the learning of high school students and the awareness of undergraduate students about the importance of interdisciplinary activities to minimize the fragmentation of knowledge was observed.

\author{
Manuscrito: \\ Recebido: 18/mai/18 \\ Corrigido: $24 / j u n / 18$ \\ Aceito: 11/ago/18
}

Citation:Duarte S.G., Martins C.M.M.R., Bandeira L.G., Carramillo L.C, Gervásio C.M., Wanderley M.D.. 2018. Experiência interdisciplinar na educação básica e na formação de professores: Artes, Biologia e Geociências. Terræ Didatica, 14(3):245-255. URL: http://www.ige.unicamp.br/terraedidatica/.

Keywords: Education, evolution, Paleontology, didactics.

\section{Introdução}

O conceito de interdisciplinaridade vem sendo discutido nos diferentes âmbitos científicos e muito fortemente na educação (Thiesen 2008). Segundo Thiesen (2008), interdisciplinaridade é uma reação alternativa à abordagem disciplinar normalizadora dos diversos objetos de estudo. A interdisciplinaridade prega a possibilidade de superar a fragmentação das ciências e dos conhecimentos produzidos pelas mesmas e na qual simultaneamente se exprime a resistência sobre um saber parcelado, seja no ensino ou na pesquisa. A interdisciplinaridade, como um enfoque teórico-metodológico surge na segunda metade do século passado como consequência de uma insatisfação da fragmentação e da especialização do conhecimento, devido ao crescimento do naturalismo e do mecanicismo científico do início da modernidade.

Para a autora Fazenda (2008), a interdisciplinaridade é mais complexa do que é dito nos textos em geral, para ela a interdisciplinaridade constitui-se na superação da ideia de fragmentação para a ideia de unidade do ser humano. Fazenda (2008) também entende que a interdisciplinaridade está relacionada com a atitude dos indivíduos frente ao conhecimento e de como transformar essa atitude em fazeres; dessa maneira, a interdisciplinaridade é mais processo do que produto.

Segundo Pires (2008), não se deve confundir o conceito de interdisciplinaridade com o de multidisciplinaridade. $\mathrm{Na}$ multidisciplinaridade cada disciplina trata de temas comuns sob sua própria ótica, articulando, algumas vezes bibliografia, técnicas de ensino e procedimentos de avaliação.

\footnotetext{
A interdisciplinaridade é ainda diferente da transdisciplinaridade. A transdisciplinaridade vai além da interdisciplinaridade e é o nível máximo de alcance de um saber unificado, que compreende as relações entre todos os saberes e que possibilita a contemplação dos saberes adjacentes, não presentes nos saberes fragmentados que nos são apresentados no ambiente acadêmico ou escolar. $\mathrm{Na}$ transdisciplinaridade, além da troca de saberes científicos, são levados em conta todos
} 
os dados e saberes humanos disponíveis e abre espaço para as percepções multiculturais, incluindo os religiosos e os mitológicos, conduzindo a uma atitude de aceitação ao desconhecido, ao inesperado e ao imprevisível (Nicolescu 1999). Este estudo focaliza a interdisciplinaridade entre ciências e artes e pode servir de arcabouço para a abordagem transdisciplinar.

A importância de praticar a interdisciplinaridade e os bons resultados que esta prática traz em sala de aula para o processo de ensino-aprendizagem não é mais novidade para os professores brasileiros. Porém, ainda são poucos os professores que desenvolvem atividades interdisciplinares.

Algumas pesquisas apontam o problema citado acima. Segundo Augusto et al. (2004), professores que foram entrevistados em suas pesquisas tinham apenas concepções rudimentares de interdisciplinaridade e a confundiam com multidisciplinaridade. Os professores afirmavam que era possível trabalhar de maneira interdisciplinar, mas não indicavam métodos adequados para fazê-lo. Em algumas pesquisas que relatam exemplos de professores que desenvolvem atividades interdisciplinares, como a pesquisa realizada por Silva \& Rodrigues (2009), são constatados relatos de professores que se queixam de uma série de barreiras que dificultam a construção de um trabalho interdisciplinar nas escolas. Questões relacionadas ao horário de trabalho fragmentado dos professores e o fato de terem que trabalhar em diferentes escolas para conseguir um salário melhor, também interferem na pouca prática da interdisciplinaridade e na interação com outros professores das diferentes disciplinas.

Sendo assim, devido à pouca prática e a dificuldade de realizar atividades interdisciplinares por alguns professores, ensinar alguns conteúdos da Biologia e da Geografia pode, por vezes, ser difícil, pois exige a conexão de diferentes áreas do saber de maneira interdisciplinar. Alguns exemplos, como ensinar sobre a origem do universo e sobre a origem e evolução da vida podem representar conteúdos complexos, com razoável grau de dificuldade, pois exigem alguma capacidade de abstração e, na maioria das vezes, causam debates e levantam polêmicas de cunho religioso em turmas do Ensino Médio e até mesmo nas turmas do Ensino Superior. Tais polêmicas, geralmente engessam e dificultam o aprendizado dos alunos.

Por isso, demonstrar aos alunos como a ciência explica o surgimento do universo, das estrelas, dos planetas, da vida e da evolução culminando em toda a biodiversidade atual contrapondo paradigmas religiosos que muitos alunos trazem consigo é um grande desafio para os professores em geral, sejam estes de Biologia, de Geografia ou de qualquer outra disciplina. Por esta razão, é muito importante nos cursos de licenciatura trabalhar esses conteúdos, ensinar estratégias e métodos de ensino-aprendizagem dos mesmos para que os futuros professores saiam preparados a lecioná-los da melhor forma possível.

Visando criar novas estratégias e alternativas de ensino-aprendizagem, foi elaborado no Colégio Estadual Professora Diuma Madeira Salles de Souza (localizado no bairro Parque Anchieta da cidade do Rio de janeiro) um projeto em parceria com a Universidade Federal Rural do Rio de Janeiro (UFRRJ) intitulado "Uma viagem na história da vida com Arte e Biologia". Concomitantemente, este projeto foi também trabalhado nas turmas de Licenciatura em Ciências Biológicas e Geografia da Universidade Federal Rural do Rio de Janeiro (UFRRJ) e da Universidade Federal do Rio de Janeiro (UFRJ), por meio das disciplinas Paleontologia Básica (IA-234), Fundamentos de Paleontologia (IA-512) e Introdução à Geologia e Paleontologia (IGL 105). O projeto também buscou de forma interdisciplinar entre Arte, Biologia e Geociências criar um método que facilitasse o aprendizado dos alunos da turma do primeiro ano do Ensino Médio (turma 1007) com relação à maneira como a ciência explica atualmente o surgimento e a evolução do universo, assim como o surgimento da vida e a sequência da evolução da mesma ao longo do tempo geológico.

O método empregado consistiu em uma sequência de aulas teóricas planejadas e posterior realização de oficinas de artes com a confecção de pinturas e esculturas com argila e gesso, ou seja, confecção de material "artístico-científico" e de cunho didático-pedagógico. Todo o material representou eventos geológicos e de evolução da vida por meio da produção de cartazes e pinturas relacionadas à formação do universo, à origem dos planetas e da confecção de réplicas de fósseis, seguindo a ordem sequencial no tempo geológico durante as aulas de Biologia, culminando em uma grande exposição no colégio.

O projeto buscou também ser exemplo de método de ensino-aprendizagem complementando a formação dos estudantes da licenciatura, que serão futuros professores, possibilitando aos 
mesmos o aprendizado de uma ferramenta didática, para que futuramente possam a vir utilizá-la com seus alunos.

\subsection{A interdisciplinaridade na Antiguidade entre arte e ciências e sua contextualização no Ensino Básico}

Desde a antiguidade, o homem representa estruturas da natureza por meio da arte e isso facilitava a comunicação e a transmissão do conhecimento como é visto por exemplo nas pinturas rupestres em diversas cavernas e nos hieróglifos egípcios. Um exemplo marcante de interação entre ciência e arte na história ocorreu durante o Renascimento, quando Leonardo da Vinci interagiu estas áreas em suas obras, como por exemplo, o Ornitóptero (equipamento de voo elaborado por Leonardo semelhante a asas, que simulava o vôo das aves e dos insetos a partir de um movimento alternativo, obtendo sustentação e propulsão). Cachapuz (2014), citando Ferreira (2008), aponta que "Leonardo foi criador na arte, descobridor na ciência e inventor na tecnologia, conseguindo integrar de maneira paradigmática ciência e arte, de tal forma que uma não seria corretamente entendida sem a outra" (Ferreira 2008 apud Cachapuz 2014).

O autor Cachapuz (2014) fez um estudo no qual apresentou uma possível abordagem no ensino das ciências nos níveis fundamental e médio, valorizando uma perspectiva interdisciplinar e envolvendo o diálogo entre arte e ciências. $\mathrm{O}$ referido autor também pressupôs a necessidade de se estabelecer uma outra relação estratégica com o conhecimento, que contrariasse e fosse mais além da segmentação e da hierarquização dos saberes que o Positivismo legitimou. Os tempos modernos exigem interdisciplinaridade, uma perspectiva de articulação de saberes, uma nova forma de compreender a relação do homem com o conhecimento.

\section{Materiais e métodos}

\subsection{Método aplicado com alunos do primeiro ano do Ensino Médio, do Colégio Estadual Professora Diuma Madeira Salles de Souza}

Durante as primeiras aulas de Biologia ministradas pela primeira autora do trabalho com a turma 1007, composta por 40 alunos, do Colégio Estadual Professora Diuma Madeira Salles de Souza foi constatado, por meio de um questionário diagnóstico mis- to (Fig. 1), um desconhecimento por parte da grande maioria dos alunos sobre a origem do universo, sobre a origem da vida, e a evolução dos seres vivos (Fig. 2). Os alunos não sabiam como a ciência explicava a origem dos mesmos, apesar de ser um assunto que aguçava a curiosidade de todos; contudo, esses alunos estavam apegados a preceitos religiosos para a compreensão dos mecanismos responsáveis pela origem do planeta Terra e dos seres vivos:

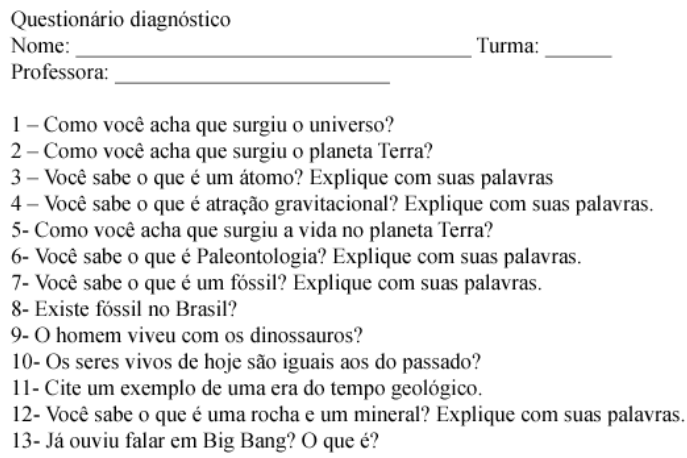

Figura 1. Questionário diagnóstico.

Após a aplicação do questionário diagnóstico foi percebido que era extremamente importante que se buscasse estratégias, métodos e alternativas para que fossem quebrados os obstáculos no ensino-aprendizagem destes conteúdos. Sendo assim, o método do projeto seguiu o seguinte processo de desenvolvimento:

Inicialmente, quatro aulas teóricas foram ministradas pela primeira autora do trabalho para a turma 1007 sobre os seguintes temas: 1- "Origem do universo, fé ou ciência?"; 2- "O surgimento e a evolução da vida no planeta Terra"; 3- "O tempo geológico"; 4- "O que é Paleontologia?" Tais temas foram contextualizados com as habilidades e competências propostas pelo currículo mínimo disponibilizado pela Secretaria de Estado de Educação (SEEDUC-RJ) para o primeiro ano do Ensino Médio. Alguns exemplos de tais habilidades e competências propostas pelo currículo mínimo são: reconhecer a existência de diferentes explicações para a origem do universo, da Terra e da vida, bem como relacioná-las a concepções religiosas, mitológicas e científicas de épocas distintas; relacionar os processos referentes à origem da vida a conceitos da Biologia e de outras ciências; reconhecer a importância da evolução na promoção de modelos, processos biológicos e organização da taxonomia dos seres vivos e reconhecer a célula como unidade morfofisiológica de todas as formas de vida. 


\begin{tabular}{l|c|c|c|c|c|c|c|c|c|c|c|c|c}
\hline Questões & Q1 & Q2 & Q3 & Q4 & Q5 & Q6 & Q7 & Q8 & Q9 & Q10 & Q11 & Q12 & Q13 \\
\hline Sim/ definiram corretamente & 35 & - & - & - & - & - & - & 15 & 15 & 22 & - & 2 & 3 \\
\hline Não & - & - & - & - & - & - & - & 22 & 25 & 8 & - & - & - \\
\hline Ouviram falar/não sabem o que é. & 3 & - & - & - & - & - & - & - & - & 10 & - & - & 17 \\
\hline Explicações religiosas & - & 35 & - & & 35 & - & - & - & - & - & - & - & - \\
\hline "Big bang" & - & 2 & - & - & - & - & - & - & - & - & - & - & - \\
\hline "Partícula minúscula" & - & - & 28 & & - & - & - & - & - & - & - & - & - \\
\hline "Terra atraindo coisas" & - & - & - & 5 & - & - & - & - & - & - & - & - & - \\
\hline "Estudo de ossos velhos, pedaços de & - & - & - & - & - & 30 & - & - & - & - & - & - & - \\
animais e coisas pré-historicas" & - & & & & & - & & & & & & & \\
\hline "Estudo de dinossauros" & - & - & - & - & - & 5 & & - & - & - & - & - & - \\
\hline Sim," restos de animais mortos" & - & - & - & - & - & - & 2 & - & - & - & - & - & - \\
\hline $\begin{array}{l}\text { Sim, "restos de animais e pessoas } \\
\text { mortas" }\end{array}$ & - & - & - & - & - & - & 3 & - & - & - & - & - & - \\
\hline Jurássico & - & - & - & - & - & - & - & - & - & - & 20 & - & - \\
\hline "É uma pedra" & - & - & - & - & - & - & - & - & - & - & - & 30 & - \\
\hline Sem resposta & 2 & 3 & 2 & 35 & 5 & 5 & 35 & 3 & - & - & 20 & 8 & 20 \\
\hline
\end{tabular}

Figura 2. Respostas dos alunos ao questionário diagnóstico. Legenda: $Q$ - questão. Números absolutos de resposta dos alunos

Posteriormente, foram planejadas oficinas de pinturas, esculturas e réplicas, de forma que os alunos pudessem expressar em suas obras, durante as oficinas, seus conhecimentos adquiridos com as aulas teóricas. O tempo de duração das oficinas também foi planejado e testado. Foram selecionados eventos como o "Big Bang" e a formação dos planetas para que os alunos os representassem por meio de pinturas.

Em seguida, foram selecionados organismos pré-históricos que pudessem ser representados por meio de esculturas e réplicas, em uma sequência de surgimento na escala do tempo geológico, para que o aluno compreendesse a evolução a partir dos organismos mais simples até os mais complexos, caracterizando um método didático a partir de uma aprendizagem lúdica, com interação de criatividade e conhecimento.

Em complementação, foi convidada uma estagiária que cursava Licenciatura em Artes para ensinar técnicas de esculturas e réplicas com argila e gesso. Após o aprendizado dessas técnicas, foram marcadas três oficinas, que ocorreram durante as aulas de Biologia. Os alunos fizeram pinturas representando o surgimento do universo e dos planetas, esculturas de organismos pré-históricos e réplicas de fósseis obtidos por doação do Departamento Nacional de Pesquisa Mineral

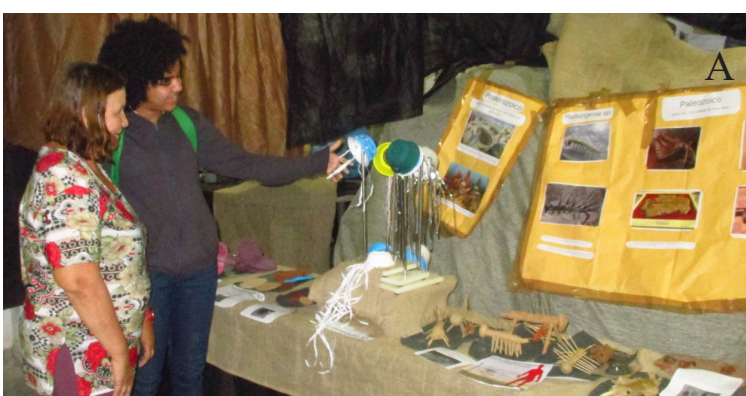

(DNPM). Os materiais utilizados foram adquiridos pelo professor responsável pela realização das oficinas, neste caso, a primeira autora, professora do Colégio Estadual Professora Diuma Madeira Salles de Souza.

Depois das pinturas e réplicas finalizadas foi solicitado a direção e a coordenação do referido colégio um espaço na unidade escolar para a exposição de todo o material produzido pelos alunos (pinturas, esculturas, réplicas) e também de outros materiais didáticos cedidos pelos autores deste trabalho, bem como doações obtidas em universidades e em outras instituições científicas (minerais, rochas, fósseis). Para tal exposição foram cedidos espaços referentes a um laboratório e depósito de livros.

A exposição teve como roteiro o surgimento do universo e terminou com a origem do homem, e foi montada de forma que cada material produzido pelos alunos fosse posicionado seguindo a ordem do tempo geológico, o que fez com que cada aluno pudesse memorizar etapas do aprendizado referente a aspectos geológicos, paleontológicos e evolutivos. Posteriormente, alguns alunos fizeram uma preparação para a apresentação da exposição por meio do estudo de textos e de capítulos de livros selecionados pela professora. Cada grupo de alunos explanou a respeito de uma Era do tempo geológico, desde o surgimento do universo e do planeta Terra até o surgimento dos seres vivos, abordando os organismos que existiram no tempo pretérito. Para isto, fizeram a utilização dos recursos didáticos, compostos pelas réplicas e pelos cartazes confeccionados, pelas rochas, minerais e fósseis, materiais estes referentes a cada período geológico. Todas as turmas da unidade escolar, bem como os professores, coordenação e direção foram convidados para a exposição (Fig. 3).

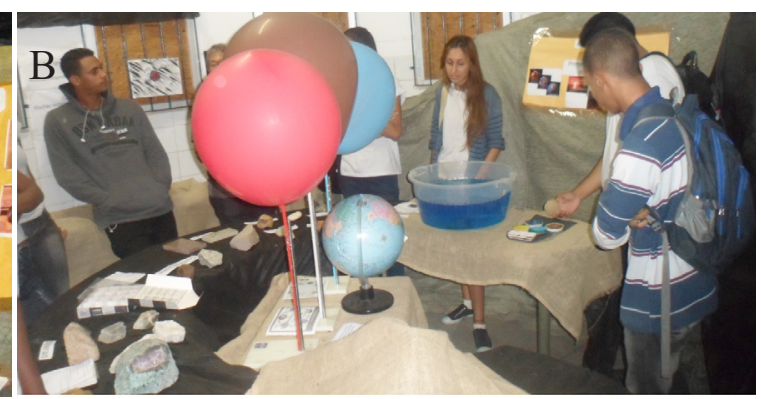

Figura 3. Diferentes alas da Exposição

\begin{tabular}{c|c|c|c|c|c}
\hline (C) Terrae Didat. & Campinas, SP & v.14 & n.3 & p. 245-255 & jul./set. 2018 \\
\hline
\end{tabular}


Antes, durante e após a realização das oficinas e da exposição, os alunos foram avaliados em diversos aspectos: participação e comparecimento na oficina e na montagem da exposição (de 0,0 a 1,5 pontos), qualidade do material produzido (de 0,0 a 1,5 pontos), domínio do tema na apresentação da exposição $(0,0$ a 2,0$)$ e questionário sobre os temas abordados $(0,0$ a 5,0$)$. Todas as avaliações unidas somaram 10,0 pontos.

\subsection{Método aplicado com os alunos da Licenciatura em Ciências Biológicas e em Geografia da UFRRJ e da UFRJ}

As turmas da Licenciatura em Ciências Biológicas e da Licenciatura em Geografia e da UFRRJ conheceram o projeto realizado no colégio por meio de uma palestra durante as aulas de Paleontologia Básica (IA-234) e de Fundamentos de Paleontologia na UFRRJ (IA-512) e na aula de Introdução à Geologia e Paleontologia na UFRJ (IGL-105). Posteriormente, foi realizada nestas turmas uma oficina (Fig. 4) igual à que foi realizada no Colégio Estadual Professora Diuma Madeira Salles de Souza após quatro aulas. Ao todo, três turmas da licenciatura, totalizando 55 alunos, foram

A

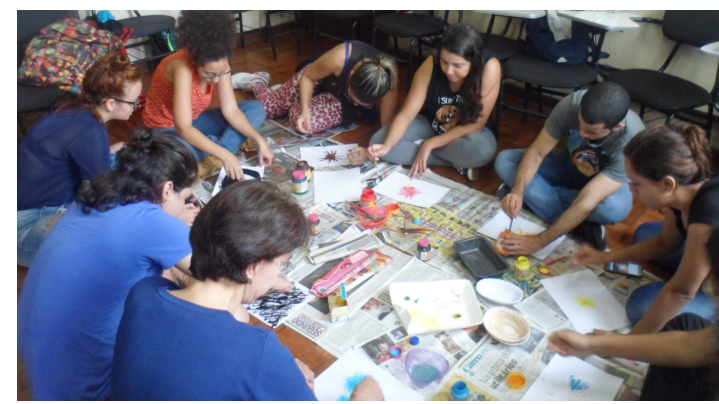

B

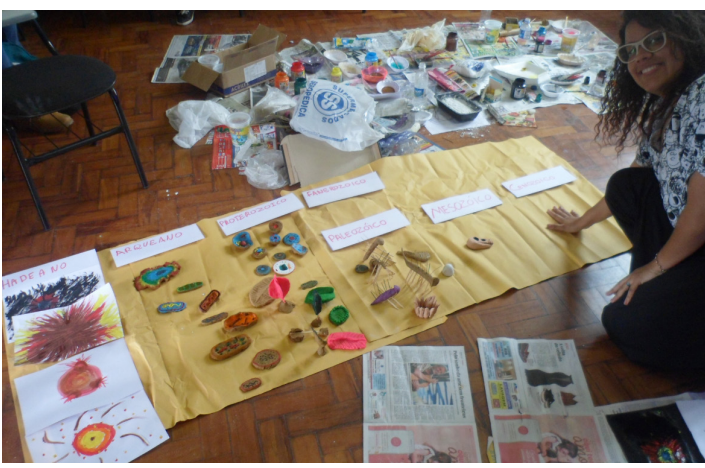

Figura 4. Alunos de Licenciatura em Ciências Biológicas e Licenciatura em Geografia durante a "Oficina": (A) fazendo pinturas representativas do surgimento do universo e da formação dos planetas, além de réplicas dos fósseis de organismos que viveram há milhões de anos; (B) organizando pinturas e réplicas de acordo com a Escala do Tempo Geológico. envolvidas e apresentadas ao projeto, sendo duas da Licenciatura em Ciências Biológicas, uma da UFRRJ e a outra da UFRJ, e uma da Licenciatura em Geografia da UFRRJ.

A palestra ministrada inicialmente para as turmas da licenciatura mostrou como ocorreu a realização do projeto no colégio, e as quatro aulas incluindo a oficina tiveram como objetivo fazer os alunos da licenciatura, futuros professores, vivenciarem de forma semelhante, o que os alunos do Ensino Médio vivenciaram.

Após a realização da oficina com os alunos da licenciatura, foi passado um questionário para que os mesmos avaliassem a oficina e o projeto como um todo, em termos de ensino-aprendizagem e pudessem fazer seus elogios, críticas e sugestões.

\subsection{Materiais utilizados nas oficinas}

Com relação aos recursos materiais, foram necessários para cada 40 alunos em média: 20 quilos de argila; 5 potes de massa de modelar de 500 gramas; $10 \mathrm{~kg}$ de gesso de secagem rápida; 2 sacos de $450 \mathrm{~g}$ de alginato (usado comumente em confecção de molde odontológico); 5 potes de tinta acrilex de diversas cores $250 \mathrm{ml} ; 1$ vidro de cola de $1 \mathrm{~kg}$; vaselina líquida; 40 pincéis de números variados; um pacote de palito de churrasco; um pacote de palito de dentes; piaçavas; $1 \mathrm{~kg}$ de feijão; $1 \mathrm{~kg}$ de arroz; fôrmas de acetato; potes vazios variados de plástico e de isopor; 5 folhas de papel cartão; 3 folhas de papel pardo; caixas de papelão; um pacote de papel ofício; fitilhos e miçangas; 10 estiletes; 10 tesouras sem ponta; retalhos de panos e de jornal.

\section{Resultados}

\subsection{Resultados do projeto no Colégio Estadual Professora Diuma Madeira Salles de Souza com os alunos da Educação Básica do primeiro ano do Ensino Médio}

\subsubsection{Exposição e material produzido pelos alunos do Ensino Médio}

A exposição do projeto realizada no colégio com todo o material produzido durante as oficinas, realizadas nas aulas de Biologia pelos alunos da turma 1007, foi apresentada: para 14 turmas do Ensino Médio (abrangendo do primeiro ao terceiro ano, cerca de 420 alunos), para seis professores, duas 
secretárias, um agente pessoal, uma coordenadora pedagógica, um diretor, uma auxiliar de serviços gerais, alguns visitantes externos e para a inspeção escolar (Fig. 3).

Alguns exemplos de materiais produzidos pelos alunos: pintura e colagem simulando o "Big Bang", a formação das estrelas e dos planetas; escultura com gesso e argila do primeiro ser vivo que surgiu há aproximadamente 3,8 bilhões de anos atrás, uma bactéria ; escultura da primeira célula eucariótica que surgiu há aproximadamente 1,7 bilhões de anos atrás; escultura dos primeiros organismos multicelulares de "corpo mole" da Fauna de Ediacara, que surgiram há aproximadamente 700 milhões de anos atrás, tais como Dickinsonia sp., Charniodiscus sp. e Cyclomedusa sp.; escultura dos organismos de "corpo duro" do Folhelho Burgess que surgiram há aproximadamente 542 milhões de anos atrás: Hallucigenia sp. (Fig. 5A), amonoide, escultura de artrópodes do Carbonífero como Meganeura sp. e Arthorpleura sp. (Fig. 5B); Anomalocaris sp.(Fig. 54C), réplicas de fósseis de peixes da Bacia do Araripe (Ceará-Brasil), escultura dos primeiros ovos com casca que surgiram no período Permiano; escultura de Archeopteryx sp. (Fig. 5D) do período Jurássico dentre outros.

Além de produzir todo este material, os alunos expuseram e apresentaram também o material didático adquirido por meio do empréstimo com as universidade e professores.

\subsubsection{Visão geral das atividades desenvolvidas pelos alunos do Ensino Médio}

Mais de 24 alunos de uma turma composta por 40 alunos participaram e tiveram bom desempenho durante a exposição. Em relação à avaliação geral, em média, as notas dos alunos referentes ao projeto foram boas, apesar de ter acontecido ausências e a falta de concentração de três alunos durante as atividades.

Quanto ao aprendizado foi constatado, por meio dos diferentes tipos de avaliações anteriormente citadas, que os alunos aprenderam a teoria do "Big Bang", a sequência de formação do planeta Terra, a sequência de surgimento dos principais grupos de organismos, a sequência dos Éons e Eras referentes a escala do tempo geológico, a idade do planeta Terra e da espécie humana, o conceito de fóssil e a importância da Paleontologia para a compreensão da evolução dos seres vivos.

Também foi notado que os alunos desinteressados da turma começaram a ser estimulados com
A

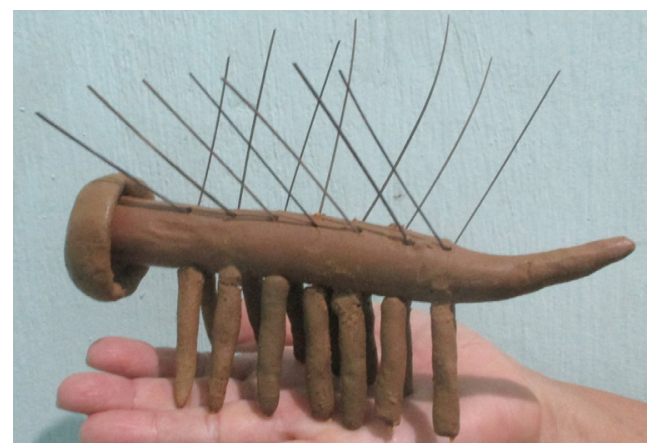

B

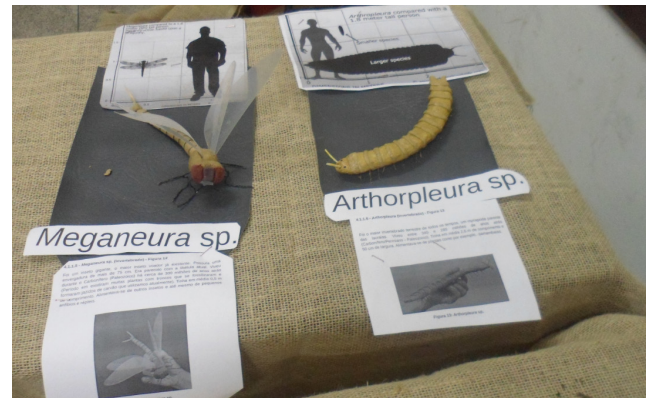

$\mathrm{C}$

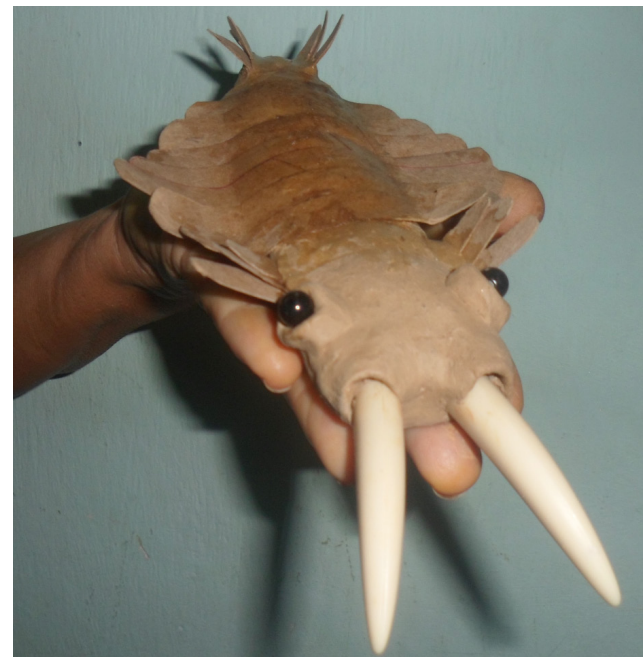

D

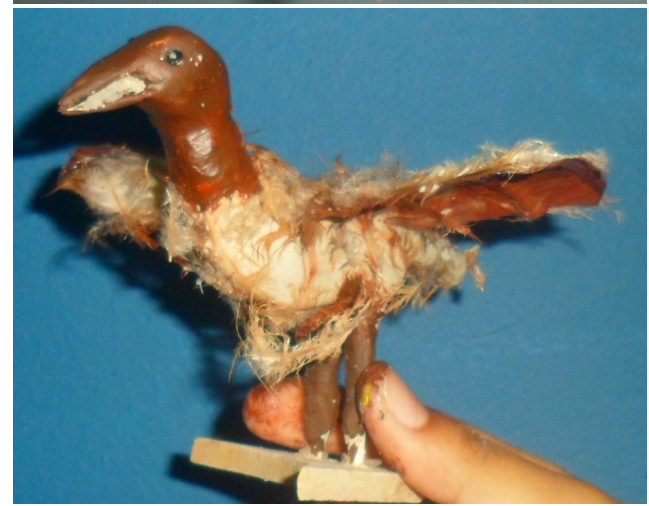

Figura 5. Réplicas produzidas pelos participantes: (A) Hallucigenia $s p$. confeccionado com argila e piaçava. (B) Meganeura $s p$. e Arthorpleura sp, confeccionados com argila, massa de modelar, plástico e tinta. Anomalocaris sp. confeccionado com argila e dente artificial. (D) Archeopteryx sp. de argila, gesso e pena de galinha feito pelos alunos. 
esta interação, pois ora descobriam e se surpreendiam com técnicas interessantes de arte para replicar os fósseis ou se encantavam com as réplicas desses organismos que viveram há milhões de anos atrás.

O estímulo produzido nos alunos com este trabalho interdisciplinar deve-se à atuação prática dos mesmos, construindo "obras de arte didáticas" com suas identidades e autonomia. Assim, o aprendizado dos alunos referente aos conteúdos propostos ocorreu de uma maneira lúdica, prazerosa e interdisciplinar: não só os alunos aprenderam, mas também a própria professora de Biologia, primeira autora do presente trabalho. A mesma teve que estudar e se atualizar bastante sobre os conteúdos de Cosmologia, Evolução e Paleontologia ao fazer o planejamento do método e das atividades. Além disso, teve que aprender sobre algumas técnicas de artes como, por exemplo, trabalhar com gesso, argila, alginato, técnicas de modelagem e técnicas de replicagem para ensinar os alunos.

Os conteúdos acima referenciados foram contextualizados com a realidade dos alunos em termos de reflexões sobre a origem do universo e da vida. As oficinas e a exposição aumentaram a autoestima da turma, que percebeu ser capaz de realizar um projeto bom e impactante.

O sucesso de um método como o desenvolvido neste projeto, que visou facilitar o processo de ensino-aprendizagem, dependeu muito de um bom planejamento. Neste caso, o planejamento envolve não só o que seria trabalhado em termos de conteúdos curriculares, mas também envolve planejamento relativo a quantidade de material e número de atividades que serão realizadas nas oficinas, proporcionalmente ao número de alunos e ao tempo disponível.

Para se fazer um bom planejamento e despertar ideias que busquem novas estratégias de ensino-aprendizagem envolvendo Biologia, Arte e Geociências é importante também que os professores durante suas graduações tenham sido formados com uma perspectiva interdisciplinar.

\subsection{Resultados da apresentação do projeto e da realização da oficina com os alunos da Licenciatura em Ciências Biológicas e em Geografia}

\subsubsection{Atividade realizada e material produzido pelos alunos da licenciatura}

A apresentação do projeto realizado no Colégio Estadual Professora Diuma Madeira Salles de
Souza recebeu muita atenção nas turmas da Licenciatura em Ciências Biológicas e em Geografia. Os alunos da licenciatura, futuros professores, demonstraram bastante interesse pelo projeto e fizeram várias perguntas de cunho metodológico. Alguns exemplos foram: De onde veio o dinheiro para financiar o material utilizado? Os alunos do Ensino Médio têm realmente interesse por esses assuntos? Quantos alunos participaram? Eles se comportaram ou fizeram bagunça?

Posteriormente, como já foi dito em relação ao método empregado, as mesmas aulas teóricas ministradas aos alunos do colégio foram ministradas para os alunos da licenciatura, assim como a oficina. Os alunos da graduação fizeram pinturas e colagem representando o "Big Bang" e a formação dos planetas, fizeram esculturas de argila e de gesso das primeiras formas de vida que surgiram no planeta Terra, réplicas e esculturas de diversos organismos que viveram há milhões de anos atrás seguindo a ordem evolutiva da escala do tempo geológico até alcançar o surgimento dos seres humanos. Em seguida, os alunos fizeram uma pequena exposição na sala de aula colocando em uma grande tabela feita em papel pardo todo o material produzido por eles (Fig. 4B).

\subsubsection{Visão geral das atividades desenvolvidas pelos alunos da licenciatura}

Ao término das atividades, 55 alunos responderam a um questionário de 8 questões, e especialmente a questão 1, a qual indagava se acharam a atividade válida para o ensino de evolução da vida, todos responderam que sim.

$\mathrm{Na}$ questão 2, na qual foi perguntando se, depois de formados, iriam fazer este tipo de atividade, apenas dois alunos disseram que não, pois seguiriam na área de pesquisa e não na licenciatura.

$\mathrm{Na}$ questão 3, em que foi perguntado se a atividade facilitou o aprendizado com relação a sequência ordenada de eventos e o surgimento dos principais grupos de seres vivos durante o tempo geológico, todos responderam que sim e não deram nenhuma sugestão de melhoria na atividade.

$\mathrm{Na}$ questão 4, em que foi perguntado o que mais gostaram na atividade, as respostas mais interessantes foram as seguintes: "Da união entre Arte e Biologia" (Aluna 1 UFRRJ), "De Construir com massinha" (Aluno 2 UFRRJ), "Do molde de gesso do peixe" (Aluna 3 UFRRJ), "Da composição dos Éons $e$ das Eras com as obras de artes" (Aluna 4 UFRRJ), “ Das Várias formas de artes, mostrando diferentes maneiras de fazer e ensinar"(Aluna 5 UFRRJ), "Da dinâmi-

\begin{tabular}{l|l} 
C Terrae Didat. & Campinas, SP
\end{tabular}

v.14

n.3

p. $245-255$ 
ca e a fácil fixação de cada Era para estudo" (Aluna 6 UFRRJ), "De realizar a confecção dos modelos" (Aluno 7 UFRRJ), "Da arte com argila” (Aluna 8 UFRRJ).

Com relação à questão 5 , que perguntou sobre o que menos gostaram, muitos deixaram em branco esta questão e os que responderam, reclamaram do tempo (que deveria ser mais estendido) e da "bagunça" produzida após a atividade.

Na questão 6, em que foi perguntado para quais séries esses alunos desenvolveriam este tipo de atividade quando fossem professores, a maior parte respondeu que seria nas séries do ensino médio e apenas dois alunos responderam nas séries do ensino fundamental, especificamente, quarto, quinto e nono ano do Ensino Fundamental.

Em relação à questão 7 em que foi perguntado se indicariam esta atividade para outros professores todos responderam que sim, e uma aluna foi enfática respondendo "Com certeza" (Aluna 1 UFRRJ).

Com relação à última questão, de número 8 , em que foi solicitado aos alunos citarem algo que tivessem aprendido, as respostas ficaram divididas. Uma parte dos alunos respondeu à pergunta com um viés de aprendizado de método de ensino, como por exemplo: "Aprendi a fazer interdisciplinaridade" (Aluna 8 UFRRJ), "Que há formas baratas e dinâmicas de ensinar" (Aluna 5 UFRRJ). Outra parte dos alunos respondeu à pergunta com um outro viés, o de aprendizado de conteúdo científico, como por exemplo: "Aprendi a sucessão dos eventos geológicos e biológicos" (Aluna 1 UFRRJ), "Aprendi a sequência de surgimento da vida" (Aluna 3 UFRRJ), "Aprendi a sequência dos Éons e das Eras e a correlação com os eventos" (Aluno 7 UFRRJ), "Aprendi a ordem das Eras" (Aluna 6 UFRRJ).

\section{Discussão}

\subsection{Discussão sobre a prática interdisciplinar}

Segundo Feistel \& Maestrelli (2012), a busca pelo desenvolvimento da interdisciplinaridade no Ensino Fundamental e Médio tem sido uma constante no meio acadêmico, mas poucas são as discussões sobre a formação de professores de forma interdisciplinar. Ainda, segundo estes autores, é óbvia a importância da discussão da interdisciplinaridade na formação inicial de professores no meio acadêmico, pois isso irá interferir no trabalho a ser realizado na Educação Básica pelos mesmos após formados. Por esta razão, o presente trabalho procurou criar este método interdisciplinar envolven- do as disciplinas de Artes, Biologia e Geociências no Ensino Médio e levou este método às turmas da licenciatura, visando melhorar a formação dos futuros professores com relação a visão interdisciplinar, envolvendo estas áreas do conhecimento.

Apesar de ser o objetivo de muitas práticas e reconhecidamente importante, o conceito de interdisciplinaridade ainda é polissêmico e o seu desenvolvimento carece de estudos, particularmente na formação inicial de professores de Ciências (Feistel \& Maestrelli 2012).

Silva \& Hornink (2011) apresentam discussões sobre interdisciplinaridade entre Biologia e Geologia, a partir de uma análise da ementa da disciplina Elementos de Geologia ministrada para o curso de Ciências Biológicas da Universidade Estadual de Campinas. Os autores focaram a importância da interdisciplinaridade:

\section{"Sabemos que a prática interdisciplinar se confi- gura como uma resposta à intensa fragmentação do conhecimento que, desde o século XIX tem se intensificado em demasia.}

Um dos argumentos para reforçar que a fragmentação entre Biologia e Geociências deva acabar é a de que o homem é um agente bio-geológico, ou seja, o homem ao atuar como agente modificador do planeta Terra atua tanto no aspecto biológico quanto no geológico.

Ao tratar de Tempo Geológico a partir do método apresentado no presente trabalho, é demonstrado aos alunos toda a interação entre os aspectos geológicos e biológicos em uma sequência evolutiva até chegar ao homem que é um agente bio-geológico transformador, como foi dito por Silva \& Hornink (2011).

Hartman \& Zimmermann (2007) publicaram um artigo intitulado "O trabalho interdisciplinar no Ensino Médio: A reaproximação das Duas Culturas" em que discutem sobre a atuação de professores de diferentes disciplinas atuando em equipe de forma interdisciplinar e observaram que para superar a lacuna de uma formação inicial em uma área específica, os professores interagiram entre si aprendendo e ensinando uns aos outros, deixando de lado a atitude de quem sabe muito a respeito de um ramo do saber e admitindo que esse saber, sendo trabalhado isoladamente e de maneira fragmentada, não responde às necessidades educacionais atuais. Isto proporcionou a cada professor conhecer melhor o trabalho dos seus colegas e a entender a importância das dife- 
rentes linguagens disciplinares para a formação do estudante.

No método apresentado no presente trabalho para o Ensino Médio, existiu a preocupação na troca do conhecimento entre a professora de Biologia da turma de primeiro ano, a estagiária em Licenciatura em Artes, os professores da licenciatura e todos os alunos envolvidos. A professora de Biologia da turma e os professores da licenciatura aprenderam técnicas artísticas e a estagiária de Artes aprendeu sobre Paleontologia e Evolução, dentre outros assuntos trabalhados. Esta interação e troca de conhecimento entra em acordo com a discussão feita por Hartman \& Zimmermann (2007).

A interdisciplinaridade desenvolvida no projeto proporcionou uma interação próxima da professora com os alunos, e esta interação foi fundamental para despertar o interesse e estimular a participação compromissada, pois a professora, ao mesmo tempo que solicita o trabalho e a participação dos alunos também deve ser um exemplo de conhecimento, de participação e de trabalho interativo com os mesmos em sala de aula ou em qualquer outra atividade didática-pedagógica.

Apesar do método do projeto ter relação com a arte, que foi adicionada a atividade para que se estimulasse a criatividade e a autonomia dos alunos quanto a sua participação, a presença da professora se fez necessária para a orientação em alguns aspectos científicos e organizacionais, servindo como aprendizado aos alunos e também para manutenção da disciplina em sala de aula. A presença e a participação da professora tiveram inspiração no modelo medieval de ensino da arte, no qual existia uma relação direta entre o mestre e o discípulo (Plaza 2003)

Esta preocupação com a interdisciplinaridade, tanto na Educação Básica quanto na Educação Superior, já alcançou até mesmo institutos de tecnologias, onde pensava-se não existir espaços para discussões deste tipo em que o enfoque seria apenas a tecnologia (Bicalho \& Machado 2015).

Bicalho \& Machado (2015) também analisaram resultados de investigação qualitativa e descritiva sobre a prática da interdisciplinaridade de docentes na graduação tecnológica do Instituto UNA de Tecnologia (Belo Horizonte, Minas Gerais), e concluíram que a intenção institucional de trabalhar de forma interdisciplinar faz parte do interesse dos professores e os mesmos têm a intenção de superar as dificuldades para a concretização desta forma de trabalhar.
No presente projeto a professora de Biologia também encontrou dificuldades para conseguir trabalhar de forma interdisciplinar em um colégio estadual, pois o horário dos professores das diferentes disciplinas é fragmentado, dificultando o diálogo e os encontros pedagógicos, além de frequentemente ocorrer o fechamento de turmas e muitos alunos apresentarem baixa frequência e também porque o sistema de ensino estadual não estimula esta prática dentre outros fatores.

\subsection{Discussão sobre a importância e 0 ensino integrado da Paleontologia e das Geociências com a disciplina Biologia}

Ao propor um método de ensino interdisciplinar como este, os autores do presente trabalho pretendem também modificar o quadro de carência no ensino de Paleontologia nas escolas estaduais do Rio de Janeiro, como já apontado por Duarte et al. (2016).

Outros trabalhos como os de Izaguirry et al. (2013), Sousa et al. (2016), Mendes et al. (2015) também discutem este quadro de carência da Paleontologia e das Geociências nas escolas do Ensino Básico, interagindo com os conhecimentos da Biologia e procurando exemplificar por meio de projetos, de trabalhos e de atividades em outros estados do Brasil.

Novais et al. (2015) averiguaram a inserção da Paleontologia no Ensino Fundamental pelo Brasil por meio de questionários em diferentes regiões, onde aconteceram projetos de extensão que levaram conhecimentos sobre Paleontologia, visando diminuir a carência nesta área do saber. Para que diminua a carência do ensino da Paleontologia e das Geociências e ocorra uma integração com as disciplinas da Educação Básica, é muito importante uma relação com as Instituições de Ensino Superior (IES). No presente trabalho, o método contou com esta inter-relação entre a escola e a universidade. A professora de Biologia manteve contato com as universidades UFRRJ e UFRJ. Isto proporcionou um "estreitamento de laços", além de ter tido a participação de um dos professores da universidade na exposição.

A relação com a universidade é extremamente importante como é apontado por Almeida et al. (2013), que avaliaram a contribuição do Laboratório de Paleontologia da Universidade Federal de Sergipe (UFS) como espaço de educação não-formal e disseminador de conhecimentos sobre Paleontologia, para alunos do $7^{\circ}$ ano das escolas 
públicas municipais de Aracaju. Este exemplo da UFS poderia vir a ser uma outra atividade incorporada futuramente no projeto pela UFRRJ e pela UFRJ em parceria com colégios estaduais, por meio da contribuição do laboratório de Paleontologia da UFRRJ e de Nanofósseis da UFRJ.

Vale também enfatizar que, para a concretização do método desenvolvido neste trabalho é importante um livro de apoio. Sendo assim, é fundamental que os professores se preocupem com a escolha do livro didático adequado e que tenha conteúdos de Paleontologia e de Geociências atualizados e detalhados, correspondentes aos conhecimentos necessários para os alunos e faixa etária dos mesmos. Zucon et al. (2010) apontam que na Educação Básica existem alguns problemas como a falta de professores capacitados, e a utilização de livros que, em sua maioria, abordam de forma inadequada e/ ou ineficiente os conceitos de Paleontologia.

Como a professora de Biologia (primeira autora) tinha formação em nível de doutorado na área de Paleontologia e trabalhou em conjunto com paleontólogos e geólogos do meio acadêmico, a mesma soube selecionar boa literatura para os alunos.

É muito relevante também ser consciente de que, ao trabalhar a Paleontologia na sala de aula, deve-se enfatizar que esta ciência não se limita apenas ao estudo dos fósseis, mas também ao estudo da Evolução, da Paleoecologia, do Paleoclima, dentre outros estudos, como é apontado por Alencar \&William (2011). Neste método interdisciplinar desenvolvido e aqui apresentado, a Paleontologia é trabalhada mostrando toda a sua abrangência, para além do simples estudo dos fósseis.

\section{Conclusão}

O método de ensino desenvolvido por meio do projeto "Uma viagem na história da vida com Arte e Biologia", elaborado para alcançar a aprendizagem dos alunos da educação básica sobre a evolução do universo e da vida ao longo do tempo geológico, mostrou-se eficaz no ensinamento desses conteúdos, a partir da utilização de diversos materiais didáticos, interagindo Artes, Biologia e Geociências. Assim, o aprendizado pôde ser facilitado com a interdisciplinaridade dessas três áreas do conhecimento, o que minimiza a fragmentação do ensino.

Da mesma forma, o método aplicado aproxima professores de diferentes áreas, promovendo uma interdisciplinaridade e uma cooperação mútua não somente entre Artes, Biologia e Geociências, mas também com outras disciplinas afins. Este método também permite estreitar relações entre professores da educação básica e professores universitários favorecendo a interação e a transmissão de conhecimentos diversificados.

Além disso, o uso desse método por meio do projeto realizado em um colégio de Ensino Médio, com turmas da Licenciatura em Ciências Biológicas e Geografia foi muito importante no sentido de melhorar a formação e a visão dos alunos, estes futuros professores, oferecendo-lhes a oportunidade de realizar uma atividade didático-pedagógica, por meio da sugestão de um método interdisciplinar mais divertido e lúdico, o que atraiu a atenção.

O apoio da direção e da coordenação do colégio foi fundamental para a escolha do espaço no qual seria realizada a exposição, já que a mesma teria que causar impacto e atrair toda a comunidade escolar, sendo importante a escolha de um local estratégico. Assim como o apoio dos departamentos das universidades, dos acadêmicos e dos universitários também.

Adicionalmente, faz-se necessário um investimento financeiro por parte da escola e do professor; todavia, é um investimento acessível, pois gesso e argila não são materiais caros e também podem ser utilizados materiais recicláveis.

É importante também que o professor tenha disposição e perseverança e saiba administrar bem o tempo entre as aulas teóricas, as oficinas, a montagem da exposição e o ensaio da apresentação da exposição, e para que tudo isso seja possível, o apoio dos pais também é fundamental.

Quanto à concretização do método por meio do projeto "Uma viagem na história da vida com Arte e Biologia” é trabalhoso, porém prazeroso. Este tipo de projeto aumenta a autoestima do professor e dos alunos, pois reflete o resultado de materiais produzidos pelos mesmos, impacta positivamente outras pessoas e é eficaz no processo de ensino-aprendizagem.

Este método didático, incluindo uma exposição, se aplicado por outros professores, pode ter um grande alcance dentro e fora da escola, a partir de uma boa divulgação do conhecimento geocientífico e biológico/evolutivo.

\section{Agradecimentos}

Os autores do presente trabalho agradecem à professora e estudante de licenciatura em Artes, Marina Barbosa Gonçalves por ensinar técnicas de artes e ajudar na realização da oficina; à direção, à 
coordenação e à representante do conselho escolar do Colégio Estadual Professora Diuma Madeira Salles de Souza, respectivamente, os professores Júlio Amaro de Albuquerque , Christina Margareth, Christina Bianchi, Adriana Zanella por permitirem e cederem espaço para a realização deste trabalho na unidade escolar e por colaborarem com a organização do evento; agradecemos também ao professor Francisco José da Silva da UFRRJ que colaborou com a exposição por meio dos conhecimentos ministrados e ao Chefe do Departamento de Geociências Heitor Farias pela permissão da realização da oficina com as turmas de graduação.

\section{Referências}

Alencar E., William R. 2013. A importância do ensino de Paleontologia e Evolução. Maiêutica, 1(1):2729.

Almeida L.F., Zucon M.H., de Souza J.F., Reis V.S., Vieira F.S. 2013. Ensino de Paleontologia: uma abordagem não-formal no Laboratório de Paleontologia da Universidade Federal de Sergipe. Terre Didatica, 10:14-21.

Augusto T.G.S., Caldeira A.M.A., Caluzi J.J., Nardi R. 2004. Interdisciplinaridade: concepções de professores da área ciências da natureza em formação em serviço. Ciência \& Educação 10(2):277-289.

Bicalho V.D.L., Machado L.R.S. 2015. O princípio da interdisciplinaridade na prática de professores da disciplina Projeto Aplicado no Instituto UNA de Tecnologia. Educação Por Escrito, 6(1):39-53.

Cachapuz A.F. 2014. Arte e ciência no ensino das ciências. Interacções, 31:95-106.

Duarte S.G., Arai M., Passos N.Z.G., Dolores M.W. 2016. Paleontologia no ensino básico das escolas da rede estadual do Rio de Janeiro: uma avaliação crítica. Anuário do Instituto de Geociências da UFRJ, 39(2):124-132.

Fazenda I.C.A. 2008. Interdisciplinaridade: História, Teoria e Pesquisa. Campinas, Papirus, 141p.

Feistel R.A.B., Maestrelli S.R.P. 2012. Interdisciplinaridade na formação inicial de professores: um olhar sobre as pesquisas em educação em ciências. $A L-$ EXANDRIA Revista de Educação em Ciência e Tecnologia, 5(1):155-176.

Ferreira P. 2008. Contributos do diálogo entre a ciência e a arte para a educação em ciências no $1^{\circ} \mathrm{CEB}$. Aveiro: Univ. de Aveiro. (Dissert. Mestr.). URL: http:// ria.ua.pt/bitstream/10773/1348/1/2009000341.pdf. Acesso 11.08.2018.
Hartmann A.M., Zimmermann E. 2007. O trabalho interdisciplinar no ensino médio: a reaproximação das "duas culturas". Revista Brasileira de Pesquisa em Educação em Ciências, 7(2):1-16.

Izaguirry B.B.D., Ziemann D.R., Muller R.T., Dockhorn J., Pivotto O.L., Costa F.M., Alves B.S., Ilha A.L.R., Stefenon V.M., Silva S.D. da. 2013. A paleontologia na escola: uma proposta lúdica e pedagógica em escolas do município de São Gabriel, RS. Cadernos da Pedagogia, 7(13):2-16.

Mendes L.A.S., Nunes D.F., Pires E.F. 2015. Avaliação do conhecimento paleontológico com intervenção em escolas de ensino médio: um estudo de caso no Estado do Tocantins. Holos, 31(8):384-396.

Nicolescu B. 1999. O Manifesto da Transdisciplinaridade. Trad. Lucia P. de Souza. São Paulo: Tirom. 153p.

Novais T., Martello A.R., Oleques L.C., Leal L.A., DaRosa A.A.S. 2015. Terre Didatica, 11(1): 33-41.

Pires M.F.C. 1998. Multidisciplinaridade, interdisciplinaridade e transdisciplinaridade no ensino. Debates, 2(2): 173-182.

Plaza J. 2003. Arte/Ciência: uma consciência. São Paulo, ARS, 1(1):37-47.

Silva F.K.M., Hornink G.G. 2011. Quando a Biologia encontra a Geologia: possibilidades interdisciplinaridades entre áreas. Rev. Educ. Ciência e Tecnologia, 4(1):117-132.

Silva O.S., Rodrigues M.A. 2009. A interdisciplinaridade na visão de professores de química do ensino médio: concepções e práticas. In: Enc. Nac. Pesq. Educ. Ciências, 7, Florianópolis, Brasil. Anais... Florianópolis. URL: http://posgrad.fae.ufmg.br/ posgrad/viienpec/pdfs/781.pdf. Acesso 05.05.2018.

Sousa R.C., da Silva I.R., dos Santos S.F., de Figueiredo, A.E.Q, Fortier D.C. 2016. O ensino de Paleontologia nas escolas públicas estaduais de Floriano-PI na concepção dos docentes. In: Congresso Nacional de Educação, 3, Natal, Brasil. Anais... Natal. URL: http://www.editorarealize. com.br/ revistas/conedu/trabalhos/TRABALHO_EV056 MD4_SA18_ID10955_17082016193329. pdf. Acesso 05.05.2018.

Thiesen S.J. 2008. A interdisciplinaridade como um movimento articulador no processo ensinoaprendizagem. Rev. Bras. Educ., 13(39):545-554.

Zucon M.H. Vieira F.S. Prazeres M.F.F. Dantas M.A.T. 2010. O ensino de Paleontologia e a percepção dos alunos do curso de Biologia da Universidade Federal de Sergipe. In: Colóquio Internacional Educação e Contemporaneidade, 4, Aracaju, Brasil. Anais... URL: http://educonse.com.br/2010/ eixo_05/E5-41.pdf. Acesso 05.05.2018. 